\title{
REIMBURSED ORPHAN MEDICINES IN BULGARIA AND THE SHARE OF BIOTECHNOLOGY-DERIVED PRODUCTS
}

\author{
Assena Stoimenova ${ }^{1}$, Manoela Manova ${ }^{1}$, Alexandra Savova ${ }^{1}$, Bistra Angelovska ${ }^{2}$, Guenka Petrova $^{1}$ \\ ${ }^{1}$ Medical University, Faculty of Pharmacy, Department of Social Pharmacy and Pharmacoeconomics, \\ Sofia, Bulgaria \\ ${ }^{2}$ Goce Delcev University, Shtip, Macedonia \\ Correspondence to: Assena Stoimenova \\ E-mail: assena_stoimenova@mail.bg
}

\begin{abstract}
Rare diseases are life-threatening or chronically debilitating conditions affecting no more than 5 in 10,000 people in the European Union. Most of the people suffering from rare diseases are actually affected by less frequently occurring diseases affecting one in 100,000 people or fewer. Almost 80\% of the rare diseases have identified genetic origins and lots of them are treated with biotechnology-derived medicinal products. The aim of our study was to evaluate the access to orphan medicines in Bulgaria based on the analysis of the Positive Drug List (PDL) and the share of biotechnology-derived products reimbursed for rare diseases in Bulgaria. Only 21 out of 56 medicines with European orphan designation and European marketing authorisation are available and funded in Bulgaria. 29\% of them are biotechnology-derived. Another 17 (out of 47) orphan medicines with European marketing authorisation and without prior orphan designations in the EU are reimbursed and 59\% of them are biotechnology-derived. Thus approximately just $37 \%$ of the orphan medicines (both with and without prior orphan designation) are available and funded in Bulgaria. Evidently the centralised marketing authorisation is not supported by the national regulatory requirements for price setting and inclusion into the PDL, which are necessary for guaranteeing medicines availability on the national market. The regulators and payers still do not ensure balance between the needs of patients and resources allocation.
\end{abstract}

Biotechnol. \& Biotechnol. Eq. 2011, 25(2), 2418-2423

Keywords: orphan medicines, biotechnology-derived products, Positive Drug List, legislation, reimbursement

\section{Introduction}

Rare diseases are life-threatening or chronically debilitating conditions affecting no more than 5 in 10,000 people in the European Union. Most of the people suffering from rare diseases are actually affected by less frequently occurring diseases affecting one in 100,000 people or fewer $(5,8,20)$.

The medicines intended for treatment of rare diseases are called "orphans" because the pharmaceutical industry has little interest, under normal market condition, in developing and marketing products intended for only a small number of patients suffering from very rare conditions $(1,2,3,4,5,9$, 11). Almost $80 \%$ of the rare diseases have identified genetic origins and a lot of them are treated with biotechnologyderived medicinal products.

Some conditions occur so infrequently that the cost of developing and bringing a medicinal product to the market, as well as the cost to society is questionable $(6,7)$. At the same time patients suffering from rare diseases should be entitled to the same quality of treatment as other patients and their medicines should be both available and affordable in the country, especially in the poor ones $(8,9)$.

Regulation (EC) No 141/2000 and Commission Regulation (EC) No $847 / 2000$ provide the legislative frame for orphan medicines and rare diseases setting up the Community procedure for designation of orphan drugs and incentives to the sponsors on a Community level $(10,11)$. Rare diseases are presented as one of the priorities in the current European Union Public Health Program running till 2013 and in addition to the initiatives on the EU level, the member-states develop further regional programmes to ensure adequate access to pharmacotherapy $(12,14,15,17,18,19)$.

The Commission recommends that Member States put in place strategies organized around national plans for rare diseases and orphan medicines, adequate mechanisms for definition, codification and inventory of rare diseases and production of good practice guidelines, fostering research on rare diseases, including cross-border cooperation, ensuring access to high-quality healthcare, in particular through identifying national and regional centres of expertise $(5,18$, 22). Some researches are pointing that there are differences in patients' access to orphan medicines in member state countries due to variety of reasons and their clarification is necessary in achieving the regulation goals $(13,21,23,24,26)$.

The aim of our study was to evaluate the access to orphan medicines in Bulgaria based on the analysis of the Positive Drug List (PDL) and the share of biotechnology-derived products reimbursed for rare diseases in Bulgaria.

\section{Materials and Methods}

A regulatory analysis of the main European and corresponding Bulgarian laws and health regulations related to rare BIOTECHNOL. \& BIOTECHNOL. EQ. 25/2011/2 
Bulgarian legislation concerning rare diseases/orphan drugs

\begin{tabular}{|c|c|c|}
\hline Law/regulation/other & Scope of the document & Relation to rare diseases/orphan drugs \\
\hline Health Act (6) & Public health care & $\begin{array}{l}\text { - Chapter } 4 \text { "Health protection of specific groups of the } \\
\text { population", section } 2 \text { "Reproductive health", paragraph } 127 \\
\text { (2), p. } 5 \text { requires prenatal diagnostics and prevention of genetic } \\
\text { diseases. } \\
\text { - Chapter } 4 \text { "Health protection of specific groups of the } \\
\text { population", section } 4 \text { "Genetic health and genetic tests", } \\
\text { paragraph 137-144 requires treatment, prevention and diagnostics } \\
\text { of genetic diseases, treatment of hereditary diseases }\end{array}$ \\
\hline $\begin{array}{l}\text { Law on Medicinal } \\
\text { Products in Human } \\
\text { Medicine (7) }\end{array}$ & $\begin{array}{l}\text { Marketing authorisation of } \\
\text { medicinal products, licensing of } \\
\text { pharmaceutical manufacturers, } \\
\text { wholesalers, retailers, clinical } \\
\text { trials, advertising, classification, } \\
\text { pharmacovigillance, state } \\
\text { control over the market, pricing } \\
\text { of medicinal products and } \\
\text { reimbursement. }\end{array}$ & $\begin{array}{l}\text { - Chapter } 3 \text { "Marketing authorisation", paragraph } 25 \text { (1): } \\
\text { reference to Regulation (EC) } 141 / 2000 \text { regarding the criteria for } \\
\text { orphan drug and paragraph } 25(\mathbf{2}) \text { which is reference to Regulation } \\
762 / 2004 \text { with regard to marketing authorisation of orphan drugs. } \\
\text { - Chapter } 3 \text { "Marketing authorisation", paragraph 27, regarding } \\
\text { the proof of orphan drug designation required as submission } \\
\text { documentation for marketing authorisation. } \\
\text { - Chapter 12 "Pricing of medicinal products", paragraph } \\
\mathbf{2 6 2} \text {, (4), p.4: orphan drugs are part of the "positive" list (the } \\
\text { reimbursement list). } \\
\text { - Definition of orphan drug is given. }\end{array}$ \\
\hline $\begin{array}{l}\text { Ministry of Health } \\
\text { Regulation No } 34 \text { as of } \\
\text { 25.11.2005 (23) }\end{array}$ & $\begin{array}{l}\text { Lays down the provisions } \\
\text { for prescribing, dispatching } \\
\text { the products for treatment of } \\
\text { diseases which are excluded } \\
\text { from the obligatory health } \\
\text { insurance. }\end{array}$ & $\begin{array}{l}\text { According to Regulation } 34 / 2005 \text {, article } 2,(1), p .4 \text { the treatment } \\
\text { of rare diseases is funded by the Ministry of Health. Obsolete as of } \\
01.01 .2007 \text {. }\end{array}$ \\
\hline $\begin{array}{l}\text { Ministry of Health } \\
\text { Regulation on Positive } \\
\text { Drug List (24) }\end{array}$ & $\begin{array}{l}\text { Lays down the provisions for } \\
\text { inclusion of medicinal products } \\
\text { into the Positive List. }\end{array}$ & $\begin{array}{l}\text { the inclusion of drugs into the positive list, including the } \\
\text { the treatment of rare diseases. }\end{array}$ \\
\hline
\end{tabular}

diseases and orphan medicines was performed (27-33). The regulatory publications were reviewed and analysed from the perspective of their role for ensuring an access to adequate pharmacotherapy.

We have applied a three-step methodology in order to assess the availability of orphan drugs in Bulgaria: (1) Review of the List of orphan medicines in Europe (with European market authorisation and with or without prior orphan designation in Europe) for orphan medicines clarification (16); (2) Review of Bulgarian PDL and identification of orphan drugs included (19); (3) Crossing the medicines identified in step (2) with the List of orphan medicines in Europe (with European market authorisation and with or without prior orphan designation in Europe) to evaluate the level of orphan drug availability in Bulgaria. The methods of manufacturing for each reimbursed orphan medicine were checked in the Summary of Product Characteristics and European public assessment reports (33).

\section{Results and Discussion}

Bulgarian legislation on orphan drugs and rare diseases Patients suffering from rare diseases in Bulgaria are estimated to be $400000-450000$ people (5). There are six disease management centres for diagnosis and treatment of rare diseases in Bulgaria. The national legislation on orphan drugs comprises of several laws and regulations as presented in Table 1, each having its role for the establishment of the legislation frame of treatment of rare diseases in Bulgaria.

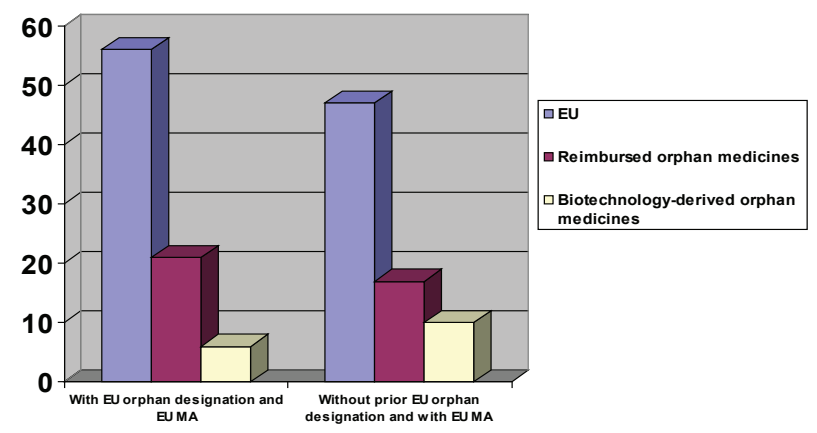

Fig. 1. Reimbursed orphan medicines and share of biotechnology-derived products

The Health Act (3) outlines the genetic examinations and prenatal tests which are aimed at limiting the incidence of rare diseases in the country. The Law on Medicinal Products in Human Medicine (4) refers to Regulation (EC) 141/2000 


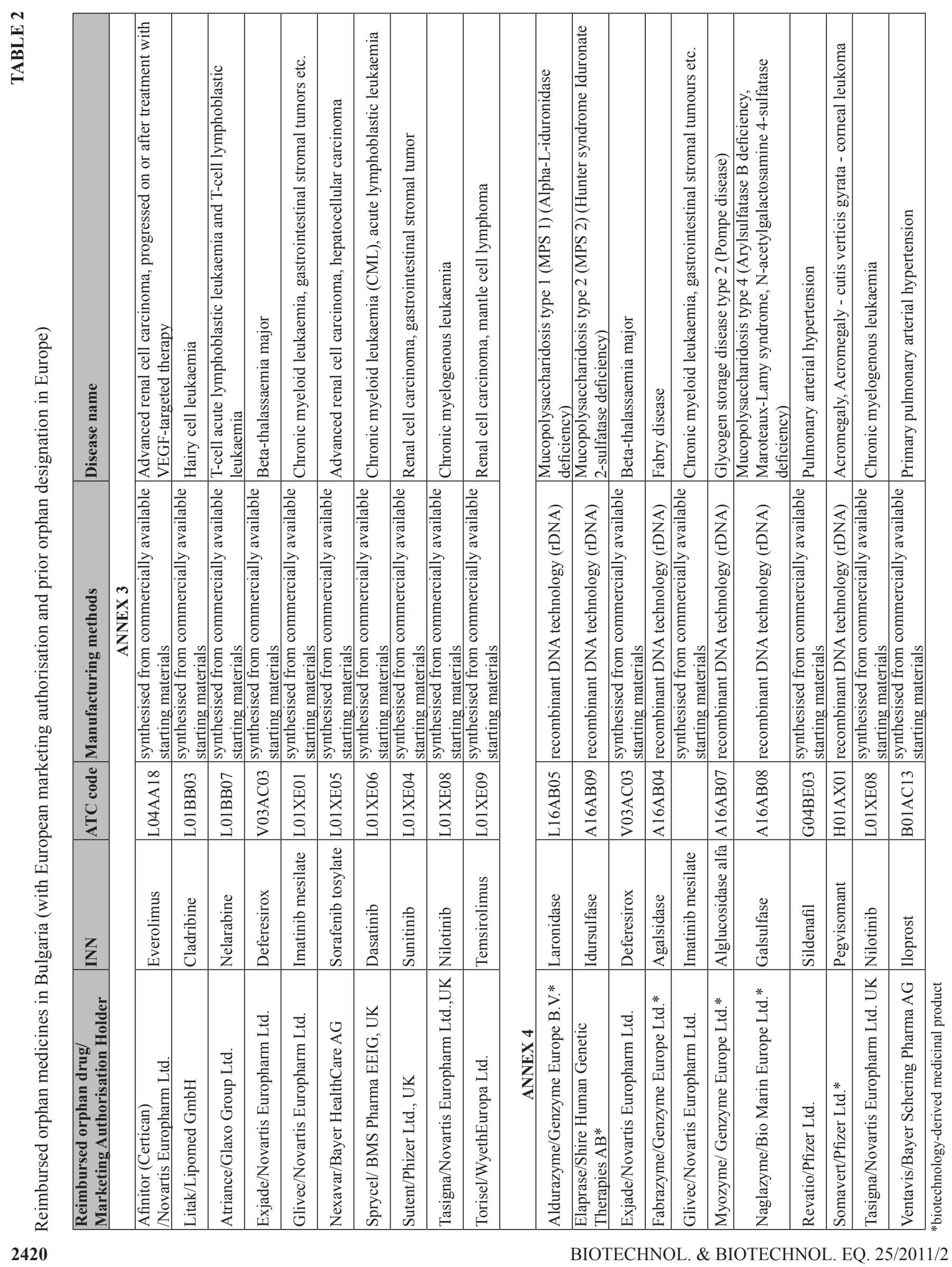


鄫 
(23) and sets up the conditions for marketing authorisation of orphan medicines, their pricing and funding. No reference is made in Bulgarian legislation to Commission Regulation (EC) No $847 / 2000$ of 27.04 .2000 laying down the provisions for implementation of the criteria for designation of a medicinal product as an orphan medicinal product. Thus no regulatory assistance is provided to the potential sponsors as intended with the Commission Regulation (EC) No 847/2000 (7), neither does a clear interpretation exist for Regulation (EC) No $141 / 2000$ requirements at a national level.

The orphan medicines are authorised through the centralised procedure but in order to make them affordable on a national level a price need to be registered and a procedure for funding need to be regulated. Both processes are controlled by the Ministry of Health in Bulgaria.

Once included in the PDL, the orphan medicines are funded either by the Health Insurance Fund or by the state budget for the diseases which are excluded from the scope of the obligatory health insurance.

\section{Analysis of the orphan medicines included in the Bulgarian Positive Drug List}

The Bulgarian Positive Drug List (19) consists of four annexes which are divided based on the sources of funding. For the purpose of this publication we studied the orphan medicines, which are included in Annexes 3 and 4 and are fully reimbursed by the state budget.

Our analysis is separated in two parts- availability of orphan medicines with European marketing authorisation and prior orphan designation in Europe, and availability of orphan medicines with European marketing authorisation and without prior orphan designation in Europe into the Bulgarian PDL.

The orphan medicines with European marketing authorisation and prior orphan designation in Europe that are included in the Bulgarian PDL are presented in Table 2. There are 21 orphan medicines identified (10 in Annex 3 and 11 in Annex 4), representing treatment for 6 anatomical systems, but mainly various types of leukaemia, renal cell carcinoma, mucopolysaccharidosis, acromegaly etc. It is necessary to clarify that the list with medicines also provides the list with specific diagnoses for which they are funded.

The orphan medicines with European marketing authorisation and without prior orphan designation in Europe available in Bulgarian PDL are presented in Table 3. We have identified 17 orphan medicines (16 in Annex 3 and 1 in Annex 4) representing treatment for diseases of 3 anatomical systems: haemophilia, thalassaemia, various types of cancer, juvenile idiopathic arthritis etc.

The relative shares of both studied groups of orphan medicines which are reimbursed in Bulgaria are presented in Fig. 1. In comparison with all orphan medicines centrally placed on the market only 21 out of 56 with European orphan designation and European marketing authorisation are available and funded in Bulgaria. 29\% of them are biotechnology-derived. Another 17 (out of 47) orphan medicines with European marketing authorisation and without prior orphan designation in EU are reimbursed and $59 \%$ of them are biotechnology-derived. Thus approximately $37 \%$ of the orphan medicines (both with and without prior orphan designation) are available and funded in Bulgaria.

Although there are a lot of initiatives regarding the rare diseases and orphan medicines at the national level it is evident that still the Bulgarian legislation is not fully harmonised with the corresponding European documents (33). There are chapters dealing with rare diseases in the Health Act and with orphan medicines in the Law on Medicinal Products but a lot of other elements are missing as are the cooperation with marketing authorisation holders and full harmonisation with the European regulatory policy. Thus patients suffering from rare diseases are also underserved in Bulgaria $(19,25,27)$.

The latter conclusion is supported by the limited availability of the orphan medicines in the Bulgarian PDL. The reasons for such a limited access could be explained with financial reasons or with the existing therapeutic practice $(9,12)$. Unfortunately we do not possess the patient registries for all rare diseases, as well as official information about all the patients using orphan medicines and we could not evaluate their usage and compare with other countries (27). This is a major limitation of our study. Further studies need to be done to clarify the real patient access in respect of the financial affordability of main and supporting therapy.

The fact that only $37 \%$ of all medicines with orphan designation are available in the list with reimbursed medicines is very negative and shows that a lot of efforts need to be made at the national level for ensuring better patient therapy. Evidently the centralised marketing authorisation is not supported by the following national regulatory requirements for price setting and inclusion into the PDL, which are necessary for guaranteeing medicines availability on national market. Thus we can conclude that the regulators and payers still did not ensure a balance between the needs of patients and resources allocation.

\section{Conclusions}

Although the Commission recommends that Member States put in place strategies organized around national plans for rare diseases and orphan medicines, ensuring access to highquality healthcare, there are significant differences in orphan drug availability amongst the countries. The access to orphan medicines through the Bulgarian PDL is limited for patients with rare diseases and further studies about their affordability both for the reimbursement system and for the patients need to be done. The Bulgarian health legislation needs of further development to introduce important European requirements concerning the access to orphan medicines. The lack of national guidelines on treatment of rare diseases did not allow us to assess the availability of supportive treatment. We could recommend establishment of disease management national guidelines focused not only on orphan drugs but on patient and his/her disease including non-orphan treatment. 


\section{REFERENCES}

1. Ayme S. and Schmidtke J. (2007) Bundesgesundheitsblatt Gesundheitsforschung Gesundheitsschutz, 50(12), 14771483.

2. Baumevieille M., Daveluy A., Aulois-Griot M., Haramburu F (2007) Therapie. 62(1), 9-16.

3. Bulgarian Health Act (2004) State Gazette №70/10 Aug. 2004.

4. Bulgarian Law on Medicinal Products in Human Medicine (2007) State Gazette №31/13 Apr. 2007.

5. Bulgarian National Plan for Rare Diseases (2009-2013) (genetic, birth defects and noninherited diseases), Ministry of Health, Republic of Bulgaria.

6. Chokshi D.A. (2006) PloS Med., 3(6), e136.

7. Commission Regulation (2000) Commission Regulation (EC) No 847/2000 of 27 April 2000 laying down the provisions for implementation of the criteria for designation of a medicinal product as an orphan medicinal product and definition of the concepts "similar medicinal product" and "clinical superiority".

8. Communication from the Commission to the European Parliament, the Council, the European Economic and Social Committee and the Committee of the Regions on rare diseases: Europe's challenges.

9. Drummond M.F., Wilson D.A., Kanavos P., Ubel P., Rovira J. (2007) Int. J. Technol. Assess. Health Care, 23(1), 36-42.

10. Enzmann H. and Lutz J. (2008) Bundesgesundheitsblatt Gesundheitsforschung Gesundheitsschutz, 51(5), 500-508.

11. Heemstra H.E., de Vrueh R.L., van Weely S., Buller H.A., Leufkens H.G. (2008) Drug Discov. Today, 13(1516), 670-676.

12. Holding J. (2008) The Pharm. Journal, 280, 216-218.

13. Hudges D.A., Tunnage B., Yeo S.T. (2005) Q. J. Med., 98, 829-836.

14. Improving access to orphan medicines for all affected EU citizens (2010)

15.http://ec.europa.eu/pharmaforum/docs/ pricing_orphans en.pdf (Accessed Oct 2010)

16. Lavandeira A. (2002) Haemophilia, 8(3), 194-198.

17. List of orphan drugs in Europe (2009) Orphanet Report Series, Orphan Drugs collection, July 2009.
18. Matsui S. and Rounds D.E. (1971) Life Sci., 10, 217-221.

19. Minghetti P.M., Giudici E.M., Montanari L. (2000) Pharmacol. Res., 42(1), 33-37.

20. Ministry of Health in Bulgaria (2010) The Positive Drug List. www.mh.government.bg (Assessed Oct 2010).

21. Orphan drugs and rare diseases at a glance (2007) Doc. Ref. EMEA/290072/2007, European Medicines Agency, www.ema.europa.eu

22. Parisse-Brassens J. (2010) Improving patient access to orphan drugs in Europe,

23. http://www.eurordis.org/content/ improving-patientaccess-orphan-drugs-europe (Assessed Oct 2010).

24. Posada M., Martín-Arribas C., Ramírez A., Villaverde A., Abitua I. (2008) An. Sist. Sanit. Navar., 31(Suppl. 2), 9-20.

25. Regulation (1999) Regulation (EC) No 141/2000 of the European Parliament and of the Council of 16 December 1999 on orphan drugs.

26. Regulation (2005) Regulation 34/2005, on the provisions for funding the treatment of diseases excluded from the obligatory health insurance, State Gazette № 95/2005.

27. Regulation (2003) Regulation on criteria, conditions and rules for inclusion of medicinal products in positive list, State Gazette № 34/15.Apr.2003.

28. Segolene A. and Schmidtke J. (2007) Bundesgesundheitsblatt-GesundheitsforschungGesundheitsschutz, 50(12), 1477-1483.

29. Stakisatis D., Spokiene I., Juskevicius J., Valuskas K., Baiardi P. (2007) Medicina (Kaunas), 43(6), 441-446.

30. Stolk P., Heemstra H., Leufkens H.G., Bloechl-Doum B., Heerdink E.R. (2009) Orphanet J. Rare Dis., 4, 27.

31.Stolk P., Willemen M.J.C., Leufkens H.G.M. (2006) Bull. World Health Organ., 84(6), 745-751.

32. Taruscio D., Trama A., Stefanov R. (2007) Folia Med (Plovdiv), 49(1-2), 59-67.

33. Trouiller P., Torreele E., Olliaro P., White N., Foster S., Wirth D., Pecoul B. (2001) Trop. Med. Int. Health, 6(11), 945-951.

34. Watson R. (2000) BMJ, 320(7245), 1294.

35. Whyte B. (2000) Bull. World Health Organ., 78(5), 711. 